\title{
Dive, Survive or Thrive: A Prescription for Post-Traumatic Thriving
}

Randall Bell, PhD

Randall Bell is a sociologist and economist with Landmark Research Group, LLC. He specializes in disaster recovery projects worldwide. Dr. Bell completed his graduate studies at UCLA and his doctoral studies at Fielding Graduate University. He is the author of "Post-Traumatic Thriving: The Art, Science, \& Stories of Resilience."

\section{Abstract:}

Medical problems and procedures, along with a host of other issues, can be traumatizing. The fallout for post-traumatic effects can linger for decades. In any traumatic episode, the body switches off the parasympathetic (rest and digest) nervous system while turning on the sympathetic (fight-flight-freeze) system. In this mode, the body pumps high levels of adrenaline through the bloodstream. This is a basic survival instinct based on the need to escape the trauma and get to safety.

Trauma causes a well-researched chain reaction. It shifts the brain activity from the outer "human brain" to the inner "reptilian brain" that governs instincts. This can result in a blurred and distorted mental state, so when the trauma ends, many patients remain stuck in the sympathetic nervous state. It is somewhat like a car at full throttle while parked in neutral.

The human body is not designed to have a continual flow of high adrenaline levels flowing through the bloodstream. Yet, this is precisely what unresolved trauma does. This state of perpetual trauma hurts, so many self-medicate with any of the many harmful activities designed to dull the pain. Of course, self-medication only deadens the hurt but does nothing for the underlying unresolved trauma.

Health care professionals have their specialties, yet all should be versed in the fundamental steps patients can take to flip the parasympathetic nervous system back on. Two of the most effective techniques are "grounding" and "sitting in the fire." They are simple practices, can cost nothing, and get right to the heart of healing the unresolved trauma. When included in the overall prescription, both physical and emotional healing can occur.

"It had been nearly 50 years since the heart surgeons at Loma Linda University had opened up my skinny chest to perform open-heart surgery to correct a congenital defect, coarctation of the aorta. The surgery had been a complete success, right down to the fact that the surgeons never had to use any stents or synthetic materials."

\section{A Trip to the Doctor}

There I was, all wired up by my cardiologist and ready to take a treadmill stress test. Her office had a commanding view overlooking the calm Pacific Ocean. I had just walked five miles that morning and felt great. Now, I just stood there looking at the ocean, all set to go.

It had been nearly 50 years since the heart surgeons at Loma Linda University had opened up my skinny chest to perform openheart surgery to correct a congenital defect, coarctation of the aorta. The surgery had been a complete success, right down to the fact that the surgeons never had to use any stents or synthetic materials.

Since the operation, and up until now, I had enjoyed near-perfect health. My cardiologist plugged in the wires, and then a look of shock came over her face. She said, "Something is wrong." She pulled the jack out, looked at it, and plugged it back in. She then said, "Something is very wrong. Your standing pulse is 150 beats per minute." The look on her face told me that this was not good.

That moment changed everything.

While my outstanding childhood heart surgeons had corrected my physical heart problems, I had unresolved post-trauma issues related to my heart conditions. I had electrocardiograms all the time as a child, and I recall being wired up like a Christmas tree on countless occasions. As a child, my cardiologist was a woman, as was my current cardiologist as an adult. I did not recognize it, but this similar situation had triggered me. While on the outside, I looked fine, my racing heart was a clear sign that my childhood trauma had never been resolved.

It appeared to both my cardiologist and me that I was suffering from PTSD. Yet, I had been entirely unaware of it. After all, decades before the doctors told me that everything was fixed and I was good to go, and wanting to forget the whole incident, I rarely spoke about my childhood heart problems. I wanted to be a tough kid, and I stuffed those distant memories down deep.

When this all happened, I was working on my next project, a book to be called "Post-Traumatic Thriving." I knew that $66 \%$ to $85 \%$ of the population had experienced at least one trauma by college age. What I did not realize, until that day, was that I was one of them.

I had to go home and re-edit the entire book from the language of "you" to "us." I could no longer be a preacher; I was now in the same boat as the reader. I had to rewrite most of the book, as I had to accept that I was not just researching trauma recovery; I was living it.

With my childhood trauma, I had done everything exactly wrong. I did what many do in the aftermath of their trauma. Specifically, I did not talk about it. Why would I? While the hospital, doctors, 
nurses, and volunteers were terrific, and they all took excellent care of me, the whole ordeal was tough. As a young boy, it made me cry, and I believed that boys should never cry. I tried, unsuccessfully, to just forget it ever happened.

\section{"While on the outside, I looked fine, my racing heart was a clear sign that my childhood trauma had never been resolved."}

\section{Toughen Up Buttercup:}

For years, I have been a volunteer in prisons, jails, and homeless shelters. I am always surprised how often childhood trauma comes up. Child abuse is a huge problem. It is responsible for $50 \%$ of depression, $66 \%$ of alcoholism, $75 \%$ of suicide, intravenous drug use, and domestic violence. If childhood traumas were processed correctly, workplace productivity would go up, and incarceration would go down dramatically. It is clear that if we want a better world, the starting place is to address unresolved trauma.

The "judgment center" of the brain, the cerebral cortex, develops from birth to about age 21 to 26 . Damage to the cerebral cortex by trauma or abuse can impact the ability to focus and make sound judgments in adulthood. In my volunteer work in San Quentin Prison, most of the inmates suffered from covert or overt child abuse or were involved in underage drinking or drug abuse. Overt abuse is raw, physical assault, while covert abuse is mental and twists our emotions, but both cause harm.

\section{“Unresolved trauma, particularly childhood trauma, is easily the most massive problem facing humankind."}

Unresolved trauma, particularly childhood trauma, is easily the most massive problem facing humankind. Homelessness, alcoholism, drug addiction, violent crime, anger addiction, teenage pregnancy, extreme politics and religion, depression, disease, and suicide are often secondary symptoms of the underlying issue of unresolved trauma.

Emotional pain hurts. We want the pain to stop, so we stuff it. Depression and anxiety can lead to a host of issues. We usually wind up with feelings of irritability or being unsafe, not trusting others, hypervigilance, engaging in overly controlling or obsessive behaviors, taking extreme risks, having difficulty concentrating, feeling unlikable or unlovable, disordered eating, and utter hopelessness or despair.

Self-medication occurs when we attempt to suppress or withdraw from an uncomfortable reality or trauma. We try to leave it behind and escape to a place of pleasure, mystery, and even indulgence. This is understandable because life is tough, trauma hurts, and we want the suffering to stop.
Many people self-medicate because they don't have access to mental health care, so simply saying "get help" is not always useful advice. We may experience a level of pain so strong that no amount of healthy behavior can soothe us. Our "healthy" outlets themselves became triggers because they enabled us to endure the pain longer. Higher doses of prescribed medications come with their side effects.

The things we once judged, we use. The problems seem overwhelming, so some of us turn to alcohol. The problem is that alcohol creates even more depression. We may be too anxious to eat, but when we use marijuana, food suddenly tastes good again. It can also help us sleep and stave off nightmares. Like many who had unresolved traumas, I self-medicated.

Of course, self-medication can take many forms, but my personal choice was workaholism. It would be easy to say, "Well, I'm a workaholic, but at least I'm not an alcoholic." But I knew better. That would be self-righteous and hypocritical. The reality is that my choice was just as damaging as any other. It all hinders the healing, and it all causes harm.

In the aftermath of my childhood trauma, I tried to be tough and bury my feelings, which was not working out too well. Now, like anyone facing their traumas and their choices for self-medication, I began my quest to find authentic answers.

\section{"Trauma creates three choices. We can "dive" and remain stuck in the trauma indefinitely. Some work hard to overcome their traumas and 'survive." Still, others use the emotional fuel from their traumas to do something of value and "thrive."}

Trauma creates three choices. We can "dive" and remain stuck in the trauma indefinitely. Some work hard to overcome their traumas and "survive." Still, others use the emotional fuel from their traumas to do something of value and "thrive." Ultimately, I found that all post-traumatic thrivers find solutions in two simple practices, "sitting in the fire" and "grounding."

\section{Grounding:}

One day I was on a small plane that made an obscure connection from Phoenix to South Dakota. As I sat down in my airline seat, I heard a voice say, "Hey, are you Randall Bell?" I looked up and said, "Yeah. Sean?" Sean and I had been colleagues about 15 years before, and we had not seen each other since. But there he was, seated right next to me.

It was exciting to see Sean. He is a dynamic, intelligent, thoughtful guy who has a gift for creativity. Of course, we caught up on what we had both been up to.

Then Sean looked at me and said, "You know, Randall, you will not believe it, but I have been to prison." This came as a surprise, and I replied, "Wow. So, tell me about it!" Sean then told me about 
how he joined a board of directors for the Insight Prison Project, a non-profit group that reaches out to both victims and offenders and helps them heal from their trauma. I listened intently as Sean told me about going into San Quentin prison and the mind-blowing stories of life transformations.

Sean could see on my face how interested I was, and he said, "Hey, if you want to go to prison too, I can get you in!" The whole thing seemed fascinating, so I said, "Jesus taught that we should visit those in prison, and I have never done that, so I am in." I promptly submitted my paperwork and was approved by the San Quentin Warden to go inside.

Just getting inside a prison is an ordeal. First, I had to fill out a lengthy application and submit it to the warden. I found it ironic that I had to pass a criminal background check to get into prison. When I was first scheduled to go, our trip was abruptly postponed because there had been an escape attempt, and the prison went into lockdown.

After several more weeks, the day finally came when I was allowed inside. I met Sean in downtown San Francisco, and we drove over the Golden Gate Bridge to the prison. I was told not to wear anything blue or red, as those were gang colors. This left me few options, so I wore khaki trousers and a white polo shirt. I could not bring in a cell phone or any personal belongings except for my driver's license and one car key. We went to the guard office, where my ID was checked against prison records. Then we walked down a very long, concrete walkway towards the prison itself.

There another guard checked my ID a second time, searched me, and put an invisible stamp on my wrist that could only be viewed under ultraviolet light. Then I was escorted into a steel cage where the door was locked behind me, and for a third time, a guard checked my ID. When we passed this barrier, the other side's steel door was unlocked, and we went into a small holding area where we finally swung open an old, massive iron door.

Suddenly, we stood in the prison courtyard. As we walked across the concrete, I looked to my left and saw a large building that housed California's death row. We veered to the right and into a small room with cinderblock walls and plastic chairs. Then in came the inmates, all dressed in blue pants and smocks. They smiled and seemed happy to see us, and being new; I introduced myself. They all went out of their way to make me feel at ease. The chairs were arranged in a circle, and I took a seat. I had no idea what to expect.

After we received a brief welcome, we were asked to close our eyes. We went through a "grounding" exercise that others call "meditation" to avoid any perceived conflicts related to religion. I cannot explain the feeling when I realized that I was meditating for the first time while sitting between two men convicted of murder. Yet, these men were so docile and kind.

I never heard much about meditation over my entire life, nor did I have any real interest in it. That all changed that morning. I did not know it was coming. I was already uncomfortable just being there, but the experience felt surreal.

The process was simple, more of a focused-breathing exercise. All we did was sit comfortably in our chairs, close our eyes, take a few deep breaths, wiggle our toes, feel our knees, feel the pressure of the chair underneath us, wiggle our fingers, relax the muscles in our face, listen to our breathing, take several deep breaths, and open our eyes again. This is one of the most common and basic forms of "grounding," simply becoming aware of internal sensations, such as our breathing, any aches or pains, or a racing heart.

When I first began volunteering at San Quentin Prison, I was startled to learn how much the inmates practiced and enjoyed meditation as they worked to transform their lives. For virtually every prisoner I met, it was a daily practice. It is something a person can do anywhere, it costs nothing, and it offers considerable benefits. I liked it so much that occasionally I found myself repeating it when I got home.

A couple of months later, I was visiting with my cardiologist, who told me about a Harvard neuroscientist, Dr. Sarah W. Lazar, who learned about meditation by accident. Dr. Lazar had injured herself while training for the Boston Marathon. Her physical therapist told her to do stretching exercises, so Dr. Lazar took up yoga.

Dr. Lazar told reporter Melanie Curtin, "The yoga teacher made all sorts of claims that yoga would increase your compassion and open your heart, and I would think, 'Yeah, yeah, yeah, I'm here to stretch.' But I started noticing that I was calmer. I was better able to handle more difficult situations. I was more compassionate and open-hearted and able to see things from others' points of view."

Her curiosity peaked from this experience; Dr. Lazar researched the scientific literature on meditation and found evidence that the practice reduces a host of problems, such as anxiety, depression, and stress. It also improves the overall quality of life. Intrigued by both her own experience and the academic literature, Dr. Lazar began doing neuroscience research at Harvard Medical Center using brain scans.

\section{"Meditation has a host of verifiable benefits. These include cognitive thinking skills, mental health, workplace performance, relationships, and overall well-being."}

Dr. Lazar compared people who had meditated for years with others who did not meditate at all. The study showed that those who meditated had increased gray brain matter in several regions of their brains, including the areas responsible for decision-making, auditory senses, and memory. In a stunning discovery, the neurological team found that 50-year-old people who meditated had the same amount of gray matter as those who were 25 .

In another study, Dr. Lazar put people who had never meditated into an eight-week program. In only two months, the brain scans showed a measurable thickening in several brain regions responsible for learning, memory, emotions, and empathy. Their brains also revealed shrinking of the areas associated with stress, anxiety, fear, and aggression. 
Now, from both my experience as a prison volunteer and Dr. Lazar's studies, I was now convinced that "grounding" or meditation is a powerful remedy. I now have a six-inch-thick binder containing scientific studies published on the topic of meditation. Hundreds of university studies from schools such as Harvard, Stanford, Brown, Yale, UCLA, and Vanderbilt provide verifiable and reproducible studies demonstrating its effectiveness.

"Grounding" switches off the sympathetic nervous system and turns on the parasympathetic. Meditation has a host of verifiable benefits. These include cognitive thinking skills, mental health, workplace performance, relationships, and overall well-being. It also measurably reduces chronic pain, mind-wandering, fearful memories, PTSD, and symptoms related to childhood adversity.

Meditation and mindfulness also improve character and ethical behavior. Mindfulness, or the mind-body connection, simply means being present in the moment or changing our focus of awareness on the present. We are not thinking about the regrets of the past or the anxiety over tomorrow, but our minds are in the here and now. This means that we do not dwell on times outside of our current control but rather maintain a clear focus on what is happening and suspend concerns on whatever has happened or might happen. We take life one day at a time. In a mindful state, we function in sync intellectually, spiritually, and emotionally. Furthermore, it means that we are aware of our physical state-our body and our breathing. We are motivated to deliberately pause before reacting to situations in terms of what we say, think, feel, or do.

We can reflect upon how much control we have over a situation and all the possible choices and outcomes. We can note the difference between acting out or simply walking away. From this evaluation, we can see how to respond better going forward. We can use the experience to generate growth that otherwise might not have been.

While the effects are powerful, meditation is deceptively simple. We mainly focus on our breathing. Some include mantras to their reflection, such as thinking of the word "so" while inhaling and "hum" while exhaling. Some use audio-guided meditations or create visualizations to expel unwanted energy or to focus on an abstract concept, such as compassion. Blank-mind meditation is another form where we dismiss all thoughts from our minds. Some sit, some stand, some walk, and some perform yoga poses or exercise forms as in tai chi or qigong.

\section{"Grounding" or meditation lays the cornerstone for transformation. While simple, it resets our brain waves, letting the calming effects ripple out to fill our entire day. It offsets what eastern civilizations call 'monkey mind' or what westerners call 'anxiety."}

Generally, it takes 5 to 30 minutes a day to see results, but some suggest it only takes six deep breaths to get the benefits of "grounding." It may be better to have a shorter session in the morning and another in the evening, rather than one long one. It is best not to meditate right after exercising and be sitting rather than lying down. Several apps can help develop this habit. The most significant benefits come when we meditate daily, even for a few minutes. By eliminating distractions and being mindful of "now," we connect with our inner voice. If a distracting sound or thought comes to mind, we don't judge it but gently observe and bring our minds back to our breathing.

"Grounding" or meditation lays the cornerstone for transformation. While simple, it resets our brain waves, letting the calming effects ripple out to fill our entire day. It offsets what eastern civilizations call "monkey mind" or what westerners call "anxiety."

Some equate meditation with religion. As faith is a personal journey, prayer looks different to different people. However, prayer and "grounding" are two different things. "Grounding" is focusedbreathing and an effort to listen to our inner voice, while prayer is not focused on breathing but instead communicating with God or a higher power. How this is combined or not combined is a personal choice.

My cardiologist explained more about how brain waves work and prescribed 10 minutes of meditation a day, every day. I just sit comfortably, close my eyes, and focus on my breathing. It is easy, and my blood pressure dropped considerably.

Almost without exception, everyone I know who heals from trauma has a ritual of some kind, often in the early morning. They meditate, but they may also pray, stretch, read something inspirational, have a good coffee, or plan out their day. However, this is done; deep breathing exercises are at the core.

\section{"When we sit in the fire, the raw words often burn with emotion. During these moments, we can be tempted to mask the hurt with humor, sarcasm, or some other distraction, but we must sit in the fire. We must talk about that ugly stuff."}

As demonstrated from the cells in San Quentin Prison to the great halls of Harvard Medical School, "grounding" or meditation is shown to physically and emotionally heal broken hearts.

\section{Sitting in the Fire:}

With my childhood trauma, I had made the classic mistake of not talking about my heart defect or my surgery.

Society and perfectionist cultures tend to downplay the difficult experiences in life. Internal pressure builds up when we "suck it up," "sweep it under the rug," or dodge the real conversations. Not only does this prevent healing, the pressure builds up like a volcano.

I also learned about "sitting in the fire" in San Quinton Prison. This means that we are honest and have difficult conversations about what is real. We candidly discuss the details of the trauma without 
sugar-coating or glossing over anything. Opening up to these vulnerable conversations allows us to relieve the pressure.

The crimes committed by the men in San Quentin are horrific. As terrible as they are, their back-story as children is often worse. When we sit in the fire, the raw words often burn with emotion. During these moments, we can be tempted to mask the hurt with humor, sarcasm, or some other distraction, but we must sit in the fire. We must talk about that ugly stuff.

The ultimate goal is to have a conversation with a trusted person or group where we can express what really happened. It is remarkably healing to sit in the fire, and there are basically three options:

The ideal way to have a dialogue and process trauma is with a trained therapist. A competent therapist will allow us to express the full extent of the trauma without judgment and keep the conversations confidential.

\section{"A somewhat similar thing happened with me as a patient when I was told that my surgery was a success and just sent home. It is great when a war is over and wonderful to know that surgery was a success, but there is more."}

Access to therapists is limited within prisons, so they have found other ways and have turned to group therapy. We can find a trusted family member, friend, or group; however, there are two essential criteria. First, the person or group must simply listen without interrupting or being judgmental. Second, they must be trustworthy and keep our conversations strictly confidential. If these conditions are not met, this could lead to being re-traumatized.

In prison, everyone must keep the information confidential, as a leak could result in death on the prison yard or denial for parole. The process works, and for those who graduate from the program and are paroled, the recidivism rate is remarkably low.

Third, until we find a therapist or a trusted person or group, we can journal our experiences. We write about life before our trauma, the trauma itself, and what has happened since. We can maintain the journal and continue to write about the experiences as additional thoughts come to mind. Writing things down organizes our thoughts and emotions and relieves the pressure.

"Sitting in the fire" is essential. We will never heal from a trauma that we bottle up inside. While doing this, there is anything but calm. My heart races as I hear the stories. Once we are finished, there is inevitably a profound calm and immeasurable relief.

\section{A New Prescription:}

A soldier is trained to go into combat, and when the war is over, they are just sent home and expected to move on as if nothing had happened. A somewhat similar thing happened with me as a patient when I was told that my surgery was a success and just sent home. It is great when a war is over and wonderful to know that surgery was a success, but there is more.

Yes, my doctors and all the hospital staff had done a brilliant job repairing my physically damaged heart; however, what was missing was that I had undergone a traumatic childhood experience that would stick with me for decades. I am not alone. Millions undergo traumatic experiences, so these principles, coming from the health professionals that we trust, are enormously helpful for complete healing.

It is useful to know that, with simple practices, we can turn parasympathetic and sympathetic nervous systems, on or off. For example, we can quickly flip on our sympathetic nervous system by merely watching horror movies. But the opposite is also true.

"Grounding" is medically proven to switch the body's nervous system from "stress" to "calm." These deep breathing exercises are simply taking in long, deep breaths and exhaling slowly - such as meditation or yoga exercises. Laughter, watching funny videos, telling jokes, or comedy clubs are also outstanding for flipping on the "calm" switch. Biorhythms are important, as they tell us when we are hungry, angry, lonely, or tired. Taking action flips on the parasympathetic switch. "Sitting in the fire" ultimately brings similar relief and calming results.

Trauma is complex, and many potential remedies are left for a broader discussion; however, health care professionals should know the fundamentals and integrate them into their lives and practices.

My cardiologist modeled this philosophy of total healing. She prescribed medications for my heart condition, but she did more. Like many doctors, she gave me a written prescription that included a diet and exercise regimen. Specifically, I was to cut out all added salt, processed sugar, and run at least 10 minutes a day.

"As healthcare professionals awaken to more research and realities surrounding unresolved trauma, they can care better for themselves and their patients. Of course, some patients should be referred to licensed trauma counselors; however, at a minimum, health care professionals should be aware that physical remedies are only a part of the overall healing process."

But she did not stop there. She told me to start "grounding" exercises twice a day and recommended - rather strongly - that I take a meditation class. She also took the unprecedented step of providing a safe place for me to talk about my experiences as a child who underwent open-heart surgery. She even helped me process 
my PTSD by letting me stop by her office and step onto the treadmill to overcome the triggering effect it had on me. In other words, she "sat in the fire" with me.

Today, I am no longer triggered by my childhood trauma. The results are measurable, and my heart rate while standing on a treadmill has gone from 150 to about 75 . I have successfully processed my trauma. I achieved this mainly by "sitting in the fire" and "grounding" exercises. Now when thoughts and discussions come up about my childhood trauma, they pass harmlessly through my mind without triggering my sympathetic nervous system. That is the goal of resolving our traumas.

Furthermore, as a result of my cardiologist's efforts to treat both my physical heart and post-trauma issues, my blood pressure has dropped dramatically, my energy is higher than ever, and I can now run five to ten miles, which I could never do before. At an age when people let things go, I got going.

As healthcare professionals awaken to more research and realities surrounding unresolved trauma, they can care better for themselves and their patients. Of course, some patients should be referred to licensed trauma counselors; however, at a minimum, health care professionals should be aware that physical remedies are only a part of the overall healing process.

Along with the necessary medical procedures, surgery, physical therapy, and prescription drug regimens, physicians may take a holistic approach, just as my cardiologist did. Specifically, with what is now known about resolving trauma, physicians should add two essential elements to their prescriptions, (1) deep breathing "grounding" exercises, which are proven to switch on the parasympathetic nervous system, and (2) "sitting in the fire" and not allowing those traumas to stay bottled up.

With these two practices, we not only deliberately switch on the parasympathetic nervous system, but we also help heal the body, mind, and soul.

\section{References:}

Gard, Tim, Britta K. Holzel, and Sara W Lazar. The Potential Effects of Meditation on Age-related Cognitive Decline: A Systematic Review. Annals of the New York Academy of Sciences, 2014.

Gard, Tim, Maxime Taquet, Rohan Dixit, Britta K. Holzel, Bradford C. Dickerson, and Sara W. Lazar. Greater Widespread Functional Connectivity of the Caudate in Older Adults Who Practice Kripalu Yoga and Vipassana Meditation than in Controls. Frontiers in Human Neuroscience, 2015. http://www.frontiersin.org/Human Neuroscience/10.3389/ fnhum.2015.00137/abstract.

Gard, Tim, Maxime Taquet, Rohan Dixit, Britta K. Hölzel, YvesAlexandre de Montjoye, Narayan Brach, David H. Salat, Bradford C. Dickerson, Jeremy R. Gray, and Sara W. Lazar. Fluid Intelligence and Brain Functional Organization in Aging Yoga and Meditation Practitioners. Frontiers in Aging Neuroscience, 2014. http://journal.frontiersin.org/article/10.3389/ fnagi.2014.00076/abstract.

INSIGHT PRISON PROJECT. "Trainings," n.d. http://www.insightprisonproject.org/trainings. html.

Kubler-Ross, Elisabeth. On Death and Dying: What the Dying Have to Teach Doctors, Nurses, Clergy and Their Own Fam- ilies. New York: Scribner, 1969.

Lombardo, Elizabeth. A Happy You: Your Ultimate Prescription for Happiness. Garden City, NY: Morgan James Publishing, LLC, 2010.

Lombardo, Elizabeth. Better than Perfect: 7 Strategies to Crush Your Inner Critic and Create a Life You Love. Berkeley, CA: Seal Press, 2014.

Tedeschi, Richard G., and Lawrence G. Calhoun. "Post-traumatic Growth: Conceptual Foundations and Empirical Evidence." Psychological Inquiry 15, no. 1 (2004): 1-18. https://doi. org/10.1207/s15327965pli1501 01.

Tedeschi, Richard G., and Lawrence G. Calhoun. "The Posttraumatic Growth Inventory: Measuring the Positive Legacy of Trauma." Journal of Traumatic Stress 9, no. 3 (1996): 45572. https://doi.org/10.1002/jts. 2490090305.

Tedeschi, Richard G., Elizabeth Addington, Arnie Cann, and Lawrence G. Calhoun. "Post-Traumatic Growth: Some Needed Corrections and Reminders." European Association of Personality Psychology, 2014, 350-51.

Disclosures: Dr. Bell is the author of "Post-Traumatic Thriving: The Art, Science, \& Stories of Resilience."

NT

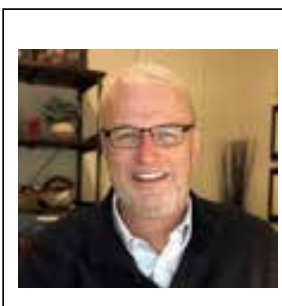

Corresponding Author

Randall Bell, PhD

UCLA - MBA

Fielding Graduate University - PhD

33071 Selva Road, Suite 230

Dana Point, CA 92651

Phone: 949-497-7600

Fax: 949-497-7601

Email: bell@landmarkresearch.com

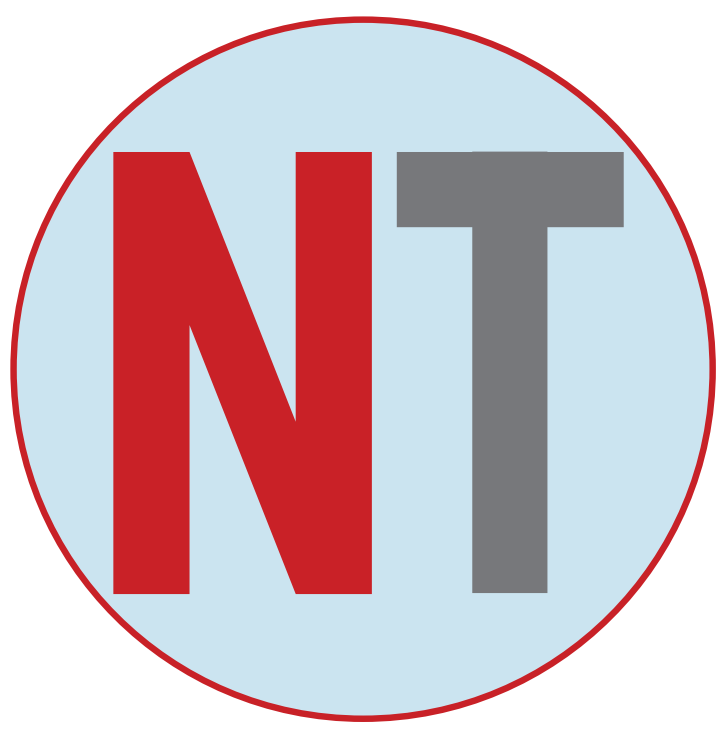

